\title{
DSC and FTIR Studies in Potassium, Strontium Doped Boro-Phosphate Glasses
}

\author{
Anand Thipperudra $^{1} \quad$ *N.Nagaraja ${ }^{2} \quad$ M. PrashanthKumar ${ }^{3} \quad$ B. Arunkumar ${ }^{1}$ \\ 1.Research Scholars, Physics Research Centre VTU, Rao bahadur Y. Mahballeswarappa Engineering College, \\ Ballari, Karnataka, India \\ 2.Professor Physics Research Centre VTU, Rao bahadur Y. Mahballeswarappa Engineering College, Ballari, \\ Karnataka, India \\ 3. Professor Dept. of physics Govt. first grade collage Kalaburagi, Karnataka, India
}

\begin{abstract}
A series of five samples of boro-phosphate glasses doped with $\mathrm{K}_{2} \mathrm{O}$ and $\mathrm{SrO}$ within the composition of $20\left(\mathrm{~B}_{2} \mathrm{O}_{3}\right)$ $+30\left(\mathrm{P}_{2} \mathrm{O}_{5}\right)+\mathrm{x}(\mathrm{SrO})+(50-\mathrm{x})\left(\mathrm{K}_{2} \mathrm{O}\right)$ where $\mathrm{x}=10,20,30,40$ and 50 were prepared by the melt quench technique. The samples were annealed to remove if any thermal strains present. The Non-crystalline nature of the glass samples was confirmed by XRD studies. The Samples were DSC studied in the temperature range from 423K to $673 \mathrm{~K}$ and glass transition temperature was determined. $\mathrm{T}_{\mathrm{g}}$ various nonlinearly with $\mathrm{SrO}$ mole fraction. FTIR study shows the existence of different structural groups such as $\mathrm{BPO}_{4}, \mathrm{BO}_{3}$ and $\mathrm{BO}_{4}$ units in the network. Borophosphate glasses containing $\mathrm{SrO}$ and $\mathrm{K}_{2} \mathrm{O}$ which exhibits different IR bands related to $\mathrm{SrO}$ structural units. In the FTIR studies the increase in number of NBO's were observed in the structure of the present glass composites with increase of $\mathrm{SrO}$ up to 30 mole fraction and further increase of $\mathrm{SrO}$ the number of NBO's decreased. Number of NBO's and glass transition temperature with mole fraction of alkaline earth ions termed as mixed cationic effect. This is for the first time the boro phosphate glasses doped with $\mathrm{K}_{2} \mathrm{O}$ and $\mathrm{SrO}$ reported for dc electrical transport and structural studies.
\end{abstract}

Keywords: Borophosphate glasses, $\mathrm{K} 2 \mathrm{O}$, SrO, NBO's, etc.

DOI: $10.7176 / \mathrm{CMR} / 12-2-01$

Publication date: February $29^{\text {th }} 2020$

\section{Introduction}

Glassy electrolytes characterized as amorphous structures are now widely used for solid state ionic devices such as lithium ion batteries, sensors, fuel cells, electro chromic displays and in high energy density batteries etc. Warburg et al in 1984 explored ion transport in glasses by applying de voltage [1-5].The ionic conductivity in oxide glass systems doped with alkali and alkaline earth ions is due to migration of ions from one ionic site to another ionic site by hopping [6-7]. However the amorphous structure and non-equilibrium nature of oxide glass systems often hinder the fundamental understanding of their ionic transport mechanism [8]. Generally the fast ion conducting glasses are formed by three components; glass network former, metal oxides acting as a glass network modifier and dopant cations. The glass network formers are oxide materials of covalent nature, the assembly of oxygen tetrahedral or trigonals for example $\mathrm{B}_{2} \mathrm{O}_{3}$ and $\mathrm{P}_{2} \mathrm{O}_{5}$ etc [9]. In ion conducting glasses the electronic contribution to the total conductivity is usually very weak, which is the consequence of periodic potential fluctuations imposed by the disordered structure [10]. Researchers reported mixed cation effect in ionic diffusivity as well as in the glass transition temperature in a glass system $\mathrm{xNa}_{2} \mathrm{O}-(1-\mathrm{x}) \mathrm{CaO}-\mathrm{SiO}_{2}$ and $\mathrm{xK}_{2} \mathrm{O}-(1-\mathrm{x}) \mathrm{BaO}-\mathrm{SiO}_{2}$ [11]. In these glasses the mixed cation effect is due to movement of two dissimilar ions of unequal size are escorted by the formation of intrinsic defects in glass forming network when mobile cation enters foreign sites. It is somewhat similar and opposite to mixed alkali effect in mixed alkali glasses but size is very less pronounced due to smaller mobility of the alkaline earth cations. In the alkali and alkaline earth glass systems the energy land scape is contain monocharge alkali ion sites and double charged alkaline earth ion sites and both types mobile cations apply either of vacant sites without readjustment [11 12 ]. The presence of single charged alkali ions in a number of alkali and alkaline earth glass systems, binary charged alkaline earth cations proved greater diffusivities than in two alkaline earth glasses $[13,14]$. In many oxide glass systems mixed cation effect has not been observed [15, 16]. Only few of the researchers reported the classical mixed cation effect in few of the oxide glass systems due to migration of single cation species [17-18]. It is known that the structure and properties of oxide glasses are strongly dependent on the nature and concentration of the constituent oxides and dopants. Although there exist numerous studies on binary and ternary tellurite and phosphate glasses containing $\mathrm{B}_{2} \mathrm{O}_{3}, \mathrm{MgO}, \mathrm{NiO}$ and $\mathrm{WO}_{3}$, on thermal and structural behavior studied in detail [19-20]. Many researchers investigate the essential information concerning the structural and compositional differences of bulk glasses using FTIR [21]. Researchers reported that the vibrational modes of the borate and phosphate networks are mainly active in three infrared spectral regions. Assignments of various peaks in the spectra have been made on the basis of literature reports [22-23]. The designation of non-bridging oxygen atoms increase with $\mathrm{BO}_{3}$ structural units and systems show bands at about 400-4000 cm-1 [24-25]. Thermal characterization (DSC/DTA) provides valuable, indirect information about the 
structural changes that take place in a glass system with the composition [26]. The change in glass transition temperature (Tg) values indicate definite changes in the glass network. The endothermic peaks corresponding to the glass transition ( $\mathrm{Tg}$ ) gives information on both the strength of inter atomic bonds and the glass network connectivity, in a similar way that the melting temperature does it for crystalline solids [27]. In many ion conducting glass systems the Nernst-Einstein relation have been used to relate the diffusion coefficient and electrical conductivity [28]. However there were not many reports in the literature on density, molar volume, dc electrical conductivity, FTIR and DSC studies on boro-phosphate glasses doped with $\mathrm{K}_{2} \mathrm{O}$ and $\mathrm{SrO}$.

In the present paper, the experimental results on XRD studies, room temperature density, molar volume, temperature dependent dc conductivity, high temperature activation energy, FTIR and DSC studies on borophosphate glass systems doped with $\mathrm{K}_{2} \mathrm{O}$ and $\mathrm{SrO}$ in the composition range $20\left(\mathrm{~B}_{2} \mathrm{O}_{3}\right)+30\left(\mathrm{P}_{2} \mathrm{O}_{5}\right)+\mathrm{x}(\mathrm{SrO})+(50$ $\mathrm{x})\left(\mathrm{K}_{2} \mathrm{O}\right)$ where $\mathrm{x}=10,20,30,40$ and 50 are presented.

\section{Theory}

2.1. Density and molar volume

The density of glass samples generally is given by Archimedes principle equation as,

$$
\rho=\frac{\mathrm{W}_{\text {air }}}{\mathrm{W}_{\text {air }}-\mathrm{W}_{\mathrm{L}}} \rho_{\mathrm{L}} \mathrm{g} / \mathrm{cm}^{3}
$$

The molar volume of the glass samples is given by the following formula,

$V_{i}=\frac{\mathrm{X}_{\mathrm{i}} \mathrm{M}_{\mathrm{i}}}{\rho_{\mathrm{i}}}$

Where ' $V_{i}$ ' molar volume, ' $x_{i}$ ' is the mole fraction, $M_{i}$ is the molecular weight and $\rho_{i}$ is the density of $\mathrm{i}^{\text {th }}$ glass sample where $i=1,2,3,4$ and $5^{\text {th }}$ glass sample. In oxide glasses mobile cationic concentration $(N)$ has been evaluated using density values and the following equation,

$N=2\left[\left(\rho m_{\text {Alkali }} / M_{\text {Alkali }} N_{A}\right]\right.$

\subsection{Electrical conductivity}

As per as many theoretical predictions and experimental results, varies theoretical models were proposed to explain the conduction mechanism in ion conducting glass systems [29-30]. However no single theoretical model investigated till today which would explain completely the ion conduction mechanism over entire temperature range. In general the total conductivity of material $\sigma_{\mathrm{T}}$ is equal to the sum of the contributions of all charge carrying species $\sigma_{i}$ and is given by

$\sigma_{i}=\Sigma_{i} \sigma_{i}=\Sigma_{i}\left(t_{i} \sigma_{i}\right)$

Where ' $t_{i}$ ' represents the transference number or the fractional contribution of a particular species of $\sigma_{T}$. For glass systems in which the conduction mechanism is dominated by a single type of ion species, for example $\mathrm{Ag}^{+}, \mathrm{Li}^{+}$, $\mathrm{K}^{+}$etc. the equation (1) simplified as,

$\sigma_{i}=\sigma_{\text {ion }}$

In general the conductivity of glass systems in which one type of mobile ion species taking part in conduction mechanism is given as,

$\sigma=n Z e \mu$

Where ' $n$ ' is the number of mobile ions per unit volume and ' $\mu$ ' is the mobility. Both are temperature dependent. Nernst-Einstein assumed the equivalence of the gradient in particle concentration which results from driving force for diffusion equal to external force. In case of ionic conduction the drift force is related to applied electric field, and Nernst-Einstein obtained the expression for diffusion coefficient and is given by the relation i.e.

$\mathrm{D}(\sigma)=\frac{\sigma k T}{n(Z e)^{2}}$

Where ' $D$ ' the diffusion coefficient, ' $\sigma$ ' the electrical conductivity, ' $k$ ' the Boltzmann constant, ' $T$ ' the temperature of the glass system, ' $n$ ' the mobile cation concentration, ' $Z e$ ' the charge of the ion. From statistical random walk calculations on the basis of thermal activated process, the free energy for motion of cations for electrical conductivity in the oxide glass systems is given by [7],

$\sigma=\frac{N e^{2} l^{2} v_{0}}{6 k T} \exp \left(-\frac{\Delta G_{F}}{2 k T}\right) \exp \left(-\frac{\Delta G_{m}}{k T}\right)$

$\Delta G_{F}=\Delta H_{f}-\Delta S_{f}$ the free enthalpy associated with the formation of an interstitial ionic pair, $\Delta G_{F}=\Delta H_{f}-\Delta S_{m}$ the free enthalpy (entropy) associated with the migration of cations, $\Delta \mathrm{H}_{\mathrm{m}}$ (enthalpy of motion) is the height of the potential barrier between two sites.

For glasses in which single type of ion transport dominating, for example alkali and alkaline earth doped oxide glass systems in which alkali ion is mobile and alkaline earth ion is immobile, the electrical conductivity from the above equation Eq. (7) can be simplified as [31-32].

$\sigma T=\sigma_{0} \exp ^{\left(-\frac{E_{a}}{k T}\right)}$

Where ' $\sigma$ ' is the temperature dependent dc electrical conductivity, ' $T$ ' is the temperature of the sample and ' $\sigma_{0}$ ' is 
the pre exponential factor and is given by,

$\sigma_{0}=\frac{N e^{2} l^{2} V 0}{6 k T} \exp \left(\frac{\frac{\Delta S_{f}}{2}+\Delta S_{m}}{2}\right)$

Where ' $\mathrm{N}$ ' is the mobile cation number density, ' $\mathrm{e}$ ' the charge of the proton, $l$ is the jump distance between two adjacent ionic sites, $v_{0}$ the vibrational frequency of ion in a potential well, ' $\mathrm{k}$ ' is the Boltzmann constant, ' $\mathrm{T}$ ' is the absolute temperature, and the dc activation energy is given by the expression,

$E_{a}=\frac{\Delta H_{f}}{2}+\Delta H_{m}$

In the present work, the conductivity of the glassy system has been found to obey the Nernst Einstein relation above the glass transition temperature as given by Eq. (7). Assuming a homogenous distribution of ions in the glass, the mean jump distance between adjacent alkali ion sites is related to alkali ion concentration as $l=(1 / N)^{1 / 3}$.

\section{Experimental techniques}

The required amount of analytical grade chemicals such as Boric acid $\left(\mathrm{H}_{3} \mathrm{BO}_{3}\right)$, Ammonium Sulphate $\left(\mathrm{NH}_{4} \mathrm{H}_{2} \mathrm{PO}_{4},\right)$, Potassium Sulphate $\left(\mathrm{K}_{2} \mathrm{SO}_{4}\right)$ and Strontium oxide $(\mathrm{SrO})$ were thoroughly mixed by manually grinding in an aget mortar then transferred to porcelain crucible. The grinded chemicals mixture was heated to melting temperature at $1253 \mathrm{~K}$ in a high temperature electrical muffle furnace. When homogeneous transparent melt was formed, then the melt was rapidly quenched using two stainless steel plates and the random glass pieces formed were collected. The samples were subjected to annealing by heating them for an hour up to $573 \mathrm{~K}$ and left them for slow cooling for 4 hour.

The samples were subjected to X-ray diffraction studies using Bruker D8 Advanced Diffractometer at IISER, Pune.

Room temperature density, $\rho$ was determined by following Archimedes principle equation (1) using sensitive single pan balance (Citizen Cy204) with an accuracy of $0.1 \mathrm{mg}$ and toluene $\mathrm{C}_{7} \mathrm{H}_{8}$ as an immersion liquid.

Glasses were well shaped to the required sizes for the measurement of dc conductivity. The thickness of the samples was lying between $1.3 \mathrm{~mm}$ to $2.5 \mathrm{~mm}$ and the cross sectional area ranging between $1.5 \mathrm{~mm}^{2}$ to $1.8 \mathrm{~mm}^{2}$. Silver paste was painted on two major surfaces of the samples. The DC conductivity measurements were carried out by following two-probe technique for the temperature range from $308 \mathrm{~K}$ to $503 \mathrm{~K}$. The temperature of the sample was determined to the accuracy of $\pm 1 \mathrm{~K}$ using a cromel- alumel thermocouple and digital micro voltmeter. A constant de voltage of about $5 \mathrm{~V}$ was applied across the sample. The current passing through the sample and voltage was measured with the help of a digital Pico ammeter and digital multimeter respectively to an accuracy of $\pm 0.1 \mathrm{pA}$ and \pm 10 volts. The conductivity, $\sigma$ of the samples were calculated using $\sigma=(1 / \rho)$ where the electrical resistivity, $\rho=(R A / t)$, where $R$ is resistance, ' $A$ ' the cross sectional area and ' $t$ ' thickness of the sample.

Infrared absorption spectra were recorded on a FT-IR spectrometer in the wave number range $400-4000 \mathrm{~cm}-1$ using pellets made with $\mathrm{KBr}$ and finely ground glass powder in a 20:1 ratio by weight model RX-1 FTIR spectrometer in organic chemistry lab at IISER Pune.

The glass systems were subjected to DSC studies using Differential Scanning Calorimetry model-DSC Q20 V24.11 Build 124 from room temperature to $500 \circ \mathrm{C}$ with a heating rate of $10 \circ \mathrm{C}$ per minute at common chemistry lab IIT Mumbai.

\section{Results and discussions}

\subsection{XRD Diffraction}

All the samples showed no sharp peaks in their XRD pattern [33]. The XRD pattern of one sample BPSK4 and BPSK5 is depicted in Fig 1. Similar patterns were obtained for the remaining samples which confirm the noncrystalline nature of all the samples. To save the space only the graph of two sample is depicted. 


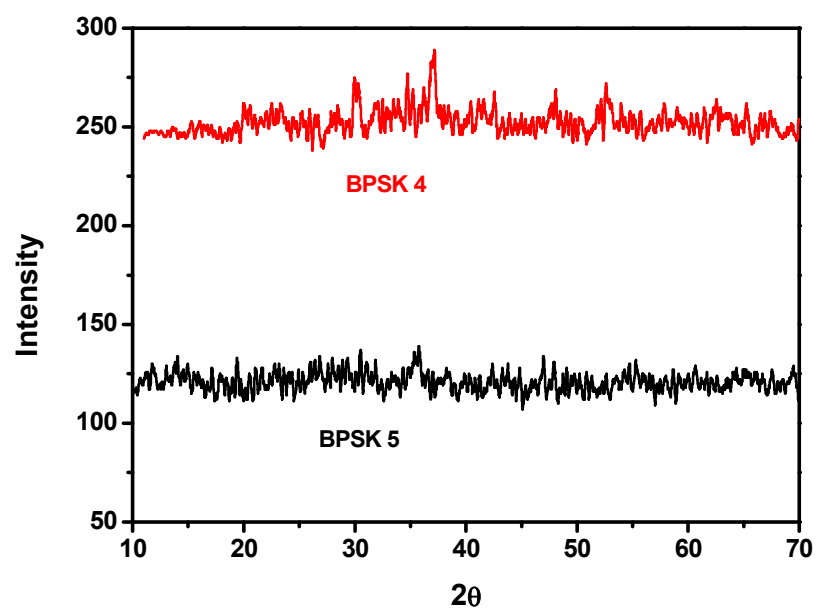

Fig.1. XRD Patterns of sample.

\section{DSC}

The temperature corresponding to the first dip has been considered to be the glass transition temperature. Similar natures of thermo grams were obtained for other four number labelled samples. Because of the availability of DSC for limited amount of time, variation of glass transition temperature versus mole fractions of SrO content is shown in figure 2.

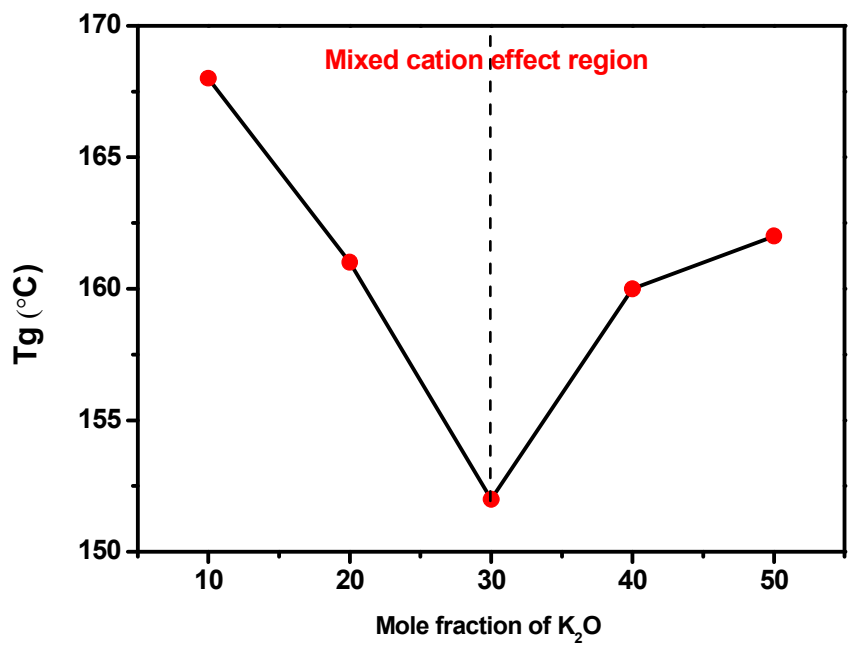

Fig.2. $\mathrm{Tg}$ (DSC) Vs Mole fraction (x) of SrO.

It can be seen that $\mathrm{Tg}$ varies non-linearly with mole fractions of $\mathrm{SrO}$ and become minimum around 0.3 . In an oxide network, $T \mathrm{~g}$ is known to depend upon the packing in the network and hence the rapid decrease of glass transition temperature in the borophosphate glasses can be related to the cross-linking of the network thus providing better thermal stability for the mixed cation effect. Thus, the variation In $T \mathrm{~g}$ with composition can be attributed to the looseness of packing in the network. DSC curves of all compositions are shown in Fig 6. In many glass systems the density and glass transition temperatures varies non linearly but initially increases up to certain mole fractions of $\mathrm{SrO}$ hits the maximum peak and further increase of $\mathrm{SrO}$ both decreases [34].

In our present glasses ' $\mathrm{N}$ ' ion concentration, ' $l$ ' jump distance, and observed the nonlinear variation in dc conductivity ' $\sigma$ ' activation energy ' $\mathrm{W}_{\mathrm{dc}}$ ', diffusion coefficient ' $\mathrm{D}$ ' and Glass transition temperature ' $\mathrm{T}_{\mathrm{g}}$ ' can be attributed that the mixed cation effect taking place at $\mathrm{x}=30$ mole fractions of SrO ion concentration. 


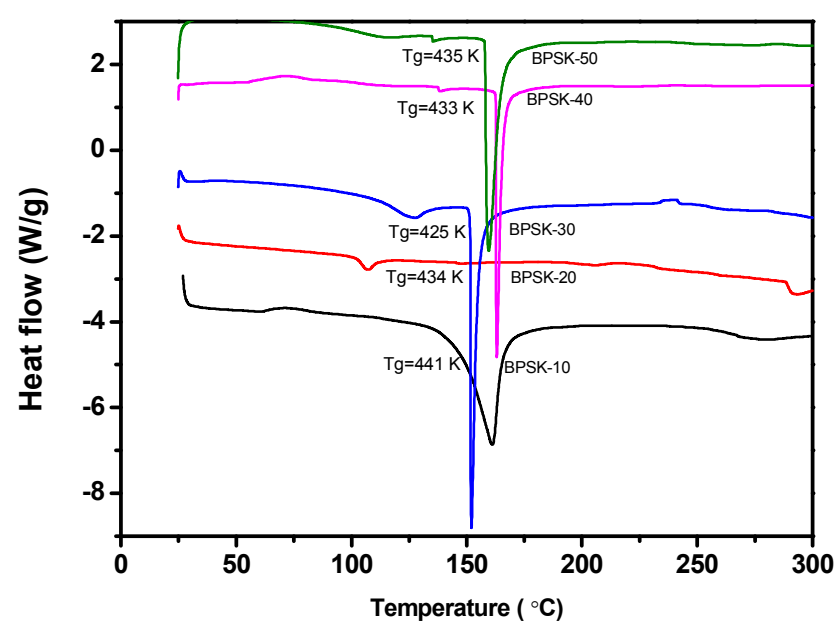

Fig.3. $\operatorname{Tg}$ (DSC) of all the 5 BPSK glass samples.

Table. 2 The variation of dc activation energy and conductivity, $\sigma$, at $500 \mathrm{~K}$

\begin{tabular}{lllllll}
\hline glass samples & $\begin{array}{c}N \\
\left(\mathrm{~m}^{-3}\right)\end{array}$ & $\begin{array}{c}l \\
(\mathrm{~nm})\end{array}$ & $\begin{array}{c}\mathrm{D} \\
\left(\mathrm{m}^{2} / \mathrm{s}\right)\end{array}$ & $\begin{array}{c}\sigma \\
\left(\mathrm{ohm} \mathrm{m} \mathrm{m}^{-1}\right)\end{array}$ & $\begin{array}{c}\mathrm{W}_{\mathrm{dc}} \\
(\mathrm{eV})\end{array}$ & $\begin{array}{c}\mathrm{Tg} \\
(\mathrm{K})\end{array}$ \\
\hline BPSK 1 & $31.97 \times 10^{28}$ & $6.788 \times 10^{-10}$ & $8.78 \times 10^{-19}$ & $1.40 \times 10^{-8}$ & 0.52 & 441 \\
BPSK 2 & $22.95 \times 10^{28}$ & $7.581 \times 10^{-10}$ & $2.16 \times 10^{-18}$ & $2.48 \times 10^{-8}$ & 0.48 & 434 \\
BPSK 3 & $8.45 \times 10^{28}$ & $0.105 \times 10^{-10}$ & $7.07 \times 10^{-17}$ & $2.98 \times 10^{-7}$ & 0.22 & 425 \\
BPSK 4 & $5.70 \times 10^{28}$ & $0.120 \times 10^{-10}$ & $4.22 \times 10^{-18}$ & $1.20 \times 10^{-8}$ & 0.48 & 433 \\
BPSK 5 & $0.749 \times 10^{28}$ & $0.237 \times 10^{-10}$ & $7.66 \times 10^{-16}$ & $1.43 \times 10^{-7}$ & 0.18 & 435 \\
\hline
\end{tabular}

\section{FTIR STUDIES}

The FTIR studies of oxide glasses gives the information not only about structure, but also about the coordination number of the compound with respect to oxygen, network formers and change in oxygen bonds of the framework which also is induced by the cations modifiers. The FTIR spectra of all the present series of samples of borophosphate glasses doped with $\mathrm{SrO}$ and $\mathrm{K}_{2} \mathrm{O}$ ions, is depicted in figure (7). The positions and assignments of the absorption bands of glasses are summarized in the table (3). Based on the literature various types of peaks, its assignments were observed [38-40], such that in the present glass series as $\mathrm{SrO}$ ion concentration increases at the cost of $\mathrm{K}_{2} \mathrm{O}$.

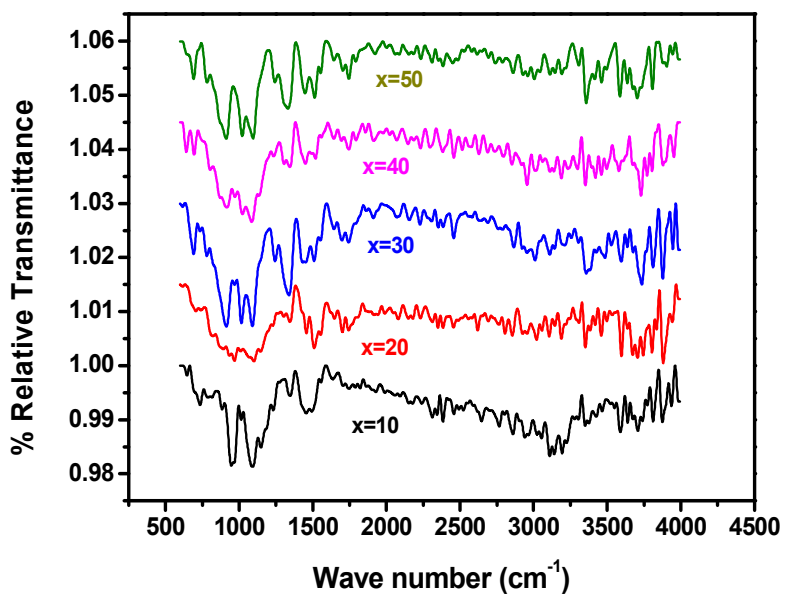

Fig.4. FTIR Spectra of all the 5 BPSK glass samples

From the figure 7. it observed that there are three distinct characteristic bands are present in the FTIR studies pattern for all the samples of borophosphate glass systems doped with $\mathrm{SrO}$ and $\mathrm{K}_{2} \mathrm{O}$, that is at

i. Between wavenumber region $600-800 \mathrm{~cm}-1$ - Various B-O-B and P-O-P bending modes in $\mathrm{BO}_{3}, \mathrm{PO}_{3}, \mathrm{BO}_{4}$ and $\mathrm{PO}_{4}$, structural units are present. 
ii. Between $800-1250 \mathrm{~cm}^{-1} \mathrm{~B}-\mathrm{O}$ stretching bond from $\mathrm{BO}_{4}$ and $\mathrm{P}-\mathrm{O}$ stretching bond from $\mathrm{PO}_{4}$ tetrahedral units are present.

iii. Between $1250-1600 \mathrm{~cm}^{-1}$ are present due to the asymmetric relaxation of $\mathrm{B}-\mathrm{O}^{-}$bonds from the $\mathrm{BO}_{3}$ units and $\mathrm{P}-\mathrm{O}^{-1}$ bonds from the $\mathrm{PO}_{3}$ structural units.

iv. The band around 913-915 $\mathrm{cm}^{-1}$ reveals the presence of $\mathrm{SrO}$ [41] and at $720 \mathrm{~cm}^{-1}$ indicates the presence of $\mathrm{K}_{2} \mathrm{O}$ in the structure of present series of glass samples.

In the spectrum the vibrational, asymmetric stretching and B-O-B network were seen at $704 \mathrm{~cm}^{-1}, 801-1098$ $\mathrm{cm}^{-1}$ and 1010-1496 $\mathrm{cm}^{-1}$, respectively. The B-O bands at 1345 and $945 \mathrm{~cm}^{-1}$ were seen for stretching vibrations both in the $\mathrm{BO}_{3}$ and $\mathrm{BO}_{4}$ units. The vibrational, asymmetric stretching and P-O-P network were seen at 616-741 $\mathrm{cm}^{-1}, 801-1098$ and 1010-1496, respectively. The B-O bands at 993 and $1094 \mathrm{~cm}^{-1}$ were seen for stretching vibrations both in the $\mathrm{PO}_{3}$ and $\mathrm{PO}_{4}$ units. The $\mathrm{P}-\mathrm{O}-\mathrm{P}$ groups were shows asymmetric stretching in IR spectrum at $886 \mathrm{~cm}^{-1}$ which confirms the chain structure of borophosphate glasses.

The wave number for particular structural units and their assignments present in the glass systems were recorded from the FTIR spectrum and depicted in the table 3 and table 4.

Table:3 FTIR band assignments of $\mathrm{BO}_{3}, \mathrm{BO}_{4}$ of $\mathrm{SrO}$ and $\mathrm{K}_{2} \mathrm{O}$ doped Boro-Phosphate glasses

\begin{tabular}{|c|c|c|}
\hline $\begin{array}{c}\text { Glass samples } \\
\text { label }\end{array}$ & Wave number $/\left(\mathrm{cm}^{-1}\right)$ & Assignments \\
\hline BPSK-10 & $\begin{array}{l}647,720,739,787,779 \\
935,967,1010,1231\end{array}$ & \multirow{5}{*}{$\begin{array}{l}600-800 \mathrm{~cm}^{-1} \text { Various } \mathrm{B}-\mathrm{O}-\mathrm{B} \text { and } \mathrm{P}-\mathrm{O}-\mathrm{P} \text { bending modes } \\
\text { in }\left[\mathrm{BO}_{3}\right]\left[\mathrm{PO}_{3}\right]\left[\mathrm{BO}_{4}\right] \text { and }\left[\mathrm{PO}_{4}\right] \text { units. } \\
800-1200 \mathrm{~cm}^{-1}-\mathrm{B}-\mathrm{O} \text { and }-\mathrm{P}-\mathrm{O} \text { bond stretching of the } \\
{\left[\mathrm{BO}_{4}\right]\left[\mathrm{PO}_{4}\right] \text { tetrahedral units. }} \\
1200-1600 \mathrm{~cm}^{-}-\text {Asymmetric stretching vibrations of B- } \\
\text { O bonds and P-O from the }\left[\mathrm{BO}_{3}\right]\left[\mathrm{PO}_{3}\right] \text { trigonal units. }\end{array}$} \\
\hline BPSK-20 & $\begin{array}{l}720,818,868,892,935, \\
945,967,969,1010, \\
1015,1065,1098,1147 \\
1234\end{array}$ & \\
\hline BPSK-30 & $\begin{array}{l}720,892,973,1022,1245, \\
1248,1337,1431,1455 \\
1507,1554\end{array}$ & \\
\hline BPSK-40 & $\begin{array}{l}720,886,971,973,1021, \\
1234,1236,, 1245, \\
1248,1266\end{array}$ & \\
\hline BPSK-50 & $\begin{array}{l}780,967,913,1014,1236 \\
3425,3420,3423 \\
3421,341\end{array}$ & \\
\hline
\end{tabular}

Table: 4 Wave numbers of $\mathrm{BO}_{3}, \mathrm{BO}_{4}, \mathrm{PO}_{3}, \mathrm{PO}_{4}$ and $\mathrm{SrO} \mathrm{K}_{2} \mathrm{O}$.

\begin{tabular}{|l|l|l|l|l|l|l|}
\hline Glass sample & $\mathrm{BO}_{3}$ & $\mathrm{BO}_{4}$ & $\mathrm{PO}_{3}$ & $\mathrm{PO}_{4}$ & $\mathrm{SrO}$ & $\mathrm{K}_{2} \mathrm{O}$ \\
\hline BPSK 1 & 1231 & 935 & 967 & 1010 & 945 & 720 \\
\hline BPSK 2 & 1234 & 945 & 969 & 1015 & 935 & 720 \\
\hline BPSK 3 & 1237 & 1022 & 973 & 1022 & 913 & 720 \\
\hline BPSK 4 & 1245 & 973 & 971 & 1021 & 913 & 720 \\
\hline BPSK 5 & 1236 & 913 & 967 & 1014 & 915 & 000 \\
\hline
\end{tabular}

The broad band at $779 \mathrm{~cm}^{-1}$ may be attributed to the symmetric stretching vibration of $\mathrm{P}-\mathrm{O}-\mathrm{P}$ rings [35]. In the spectra boroxol group ring stretching takes place between $1450-1457 \mathrm{~cm}^{-1}$ and the B-O-B vibration at 1236 $1248 \mathrm{~cm}^{-1}$. For the $\mathrm{BO}_{3}$ the bending and stretching vibrations is observed this is mainly due to the non-bridging oxygens (NBOs) at 689 and $1345 \mathrm{~cm}^{-1}$ respectively. Similarly in the Phosphate group ring stretching takes place between $1450-1457 \mathrm{~cm}^{-1}$ in the $\mathrm{P}-\mathrm{O}-\mathrm{P}$ vibration at $1245 \mathrm{~cm}^{-1}$. For the $\mathrm{PO}_{3}$ the bending and stretching vibrations is observed this is mainly due to the non-bridging oxygens (NBOs) [36]. Here, the oxygen atoms that are not shared between tetrahedral are known as non-bridging oxygen's [37]. When it links with trtrahedra together it is known as bridging oxygen. The Electrical conductivity of oxide glasses varies with variation of NBO's which results due to adding of Alkali/Alkaline earth ion [38]. In the FTIR of present series of glass samples the group of bands that occur at $1236-1496 \mathrm{~cm}^{-1}$ is due to the asymmetric stretching and the relaxation of $\mathrm{B}-\mathrm{O}$ Bond of triangle $\mathrm{BO}_{3}$ units [46]. Here when $\mathrm{SrO}$ ions added initially it converts $\mathrm{BO}_{4}$ units into $\mathrm{BO}_{3}$ and $\mathrm{PO}_{4}$ units into $\mathrm{PO}_{3}$ structural units and generates $\mathrm{BO}_{3}$ and $\mathrm{PO}_{3}$ units with $\mathrm{NBO}$ [39]. The concentration of NBO's increases with the addition $\mathrm{SrO}$ 
ions into the glass matrix up to 30 mole fraction and further increase of SrO The NBO concentration decreases [40]. The bands near 647 and $1345 \mathrm{~cm}^{-1}$ and 993 and $1094 \mathrm{~cm}^{-1}$ can be attributed to bending vibrations of $\mathrm{BO}_{3}$ and $\mathrm{PO}_{3}$ triangles and stretching vibrations of $\mathrm{BO}_{3}$ and $\mathrm{PO}_{3}$ units with non-bridging oxygen's (NBOs), respectively [41].

Correlation between dc conductivity and structure of the glasses

In oxide glasses the conductivity is directly proportional to number of NBOS [42]. The variation of the dc conductivity with the reciprocal of temperature for all compositions is shown in Fig. 1. The values of the activation energy obtained from the least squares linear fits for different compositions are given in Table 1. It is observed that the conductivity is strongly composition dependent for lower $\mathrm{SrO}$ content and higher $\mathrm{K}_{2} \mathrm{O}$ content $\mathrm{I}$.e. $\mathrm{SrO}<30$ and $\mathrm{K}_{2} \mathrm{O}>30$ mole fraction for present glass systems, while the conductivity shows a weak composition dependence for higher $\mathrm{SrO}$ and lower $\mathrm{K}_{2} \mathrm{O}$ content. In the literature no such studies were reported on borophosphate glass systems doped with $\mathrm{SrO}$ at the cost of $\mathrm{K}_{2} \mathrm{O}$. In the present glass systems the study reveals that the conductivity reaches maximum and activation energy reaches minimum, the density hits minimum value and molar volume hits peak value at 30 mole fraction of the $\mathrm{SrO}$ content. This may be due to the fact that, in these glasses the $\mathrm{BO}_{3}$ structural units with NBO's concentration increase due addition of SrO up to 30 and $\mathrm{K}_{2} \mathrm{O} 20$ mole fraction and further increase of $\mathrm{SrO}$ and decrease in $\mathrm{K}_{2} \mathrm{O}$ there is decrease in NBO's concentration[43]. It seems that the structural transformations as well as the increasing number of non-bridging oxygen's are responsible for conductivity enhancement with the increase of $\mathrm{SrO}$ and decrease of $\mathrm{K}_{2} \mathrm{O}$ content in the present glass systems for $\mathrm{SrO} \geq 30$ and $\mathrm{K}_{2} \mathrm{O} \leq 20$ mole fractions. The conductivity enhancement in this region is solely due to the increasing number of non-bridging oxygens, which are the preferential sites for the $\mathrm{K}^{+}$and $\mathrm{Sr}^{+}$ions. While the conductivity becomes less composition dependent for $\mathrm{SrO}>30$ and $\mathrm{K}_{2} \mathrm{O}<20$, as no major structural transformation occurs in this composition range.

\section{Conclusion}

A set of borophosphate glasses incorporated with $\mathrm{SrO}$ and $\mathrm{K}_{2} \mathrm{O}$ have been prepared and has been characterized through XRD, FTIR and DSC studies. Their non-crystalline nature was confirmed by XRD, The samples were measured for room temperature density and molar volume was estimated. The density and molar volume behaves in opposite fashion and nonlinear with increasing mole fractions of $\mathrm{SrO}$ and hits minimum and maximum peaks respectively at 30 mole fraction of SrO. The high temperature dc activation energy was determined by fitting the measured experimental data for Nernst Einstein relation. The Conductivity and activation energy found to behave in opposite fashion and hits maximum and minimum peaks respectively, at 30 mole fractions of SrO. The FTIR study shows the existence of different structural units such as $\mathrm{PO}_{4}, \mathrm{PO}_{3}, \mathrm{BO}_{3}$ and $\mathrm{BO}_{4}$ units. The observed variation of glass transition temperature with composition has been correlated with the structural modifications of the network. The nonlinear variation of the observed physical parameters such as density, molar volume, dc conductivity, high temperature activation energy, glass transition temperature, diffusion coefficient and structure with respect to mole fractions of $\mathrm{SrO}$ ion at the cost of potassium ion revealed that the classical mixed cation effect taking place in the present series of glasses.

\section{Acknowledgements}

All the authors acknowledge the rigorous research training that they received from Professor T.Sankarappa, Department of Physics, Gulbarga University, Gulbarga, India.

\section{References:}

D. Ravaine, Journal of Non-Crystalline Solids. 73, 1-3 (1985) 287.

M. Balkanski, Solid State Integrable Micro batteries (North Holland Publishing Company, Amsterdam, 1990).

G. Govindaraj, N. Baskaran, P. Manoravi, and K. Shahi, Solid State Ionics 76 (1995) 47.

T. Saito, N. Torata, M. Tatsumisago, and T. Minami, Solid State Ionics 86-88 (1996) 491.

M. Tatsumisago and A. Hayashi, J. Non3Cryst. Solids 354 (2007) 1411.

R. Kaushik, K. Hariharan, Solid State Commun. 63 (1987) 925

D. Coppo, M.J. Duclot, J.L. Souquet, Solid State Ionics 90 (1996) 111.

9 S. R. Elliott, Solid State Ionics 70371 (1994) 27.

10 W. H. Zachariasen, J. Chem. Phys. 3 (1935) 162.

11 A F. Wright et al. (eds.), Glass ... Current Issues(C) Martinus Nijhoff Publishers, Dordrecht 1985, 440.

12 Vladimir Belostotsky, Journal of Non-Crystalline Solids. 353 (2007) 1078.

13 Vladimir Belostotsky, Journal of Non-Crystalline Solids. 356 (2009) 129.

14 F. Natrup, H. Bracht, C. Martiny, S. Murugavel, and B. Roling, Phys. Chem. Chem. Phys. 4 (2002) 3225.

15 F.V. Natrup, M. Grofmeier, H. Bracht, Solid State Ionics, 180 (2009) 109. 
16 F. Branda, A. Buri, D. Caferra and A. Marotta, J. Non-Cryst. Solids 54 (1983) 193.

17 U. Tille, G.H. Frischat, and K.-J. Leers, Glastech. Ber. 51 (1978) 8.

18 F.V. Natrup, H. Bracht, S. Murugavel, and B. Roling, Phys. Chem. Chem. Phys. 7 (2005) 2279.

19 J. Briggs, Bull. Central Glass Ceram. Res. Inst. 22 (1975) 73.

20 C Martiny, S. Murugavel, B. Roling, F. Natrup, H. Bracht, and M.D. Ingram, Glass Technol. 43C (2002) 309.

21 Ersundu AE, Karaduman G, Celikbilek M, Solak N, Aydin S. Stability of the $\delta-\mathrm{TeO}_{2} \mathrm{Phase}$ in the binary and ternary TeO2 glasses. Journal of European Ceramic Society. 2010; 30:3087-3092.

22 Rada S, Rada M, Culea E. Structure and molecular modelling of tungsten borotellurate glasses. Journal of Alloys and Compounds. 2013; 552:10-13.

23 R Palani, 2 V Gobala Vijayan Volume 3; Issue 2; March 2018; Page No. 05-12 (International Journal of Advanced Science and Research) ISSN: 2455-4227.

24 C. Julien, M. Massot, M. Balkanski, A. Krol, W. Nazarewicz, Mater. Sci. Eng. B3 (1989) 307.

25 E.I. Kamitsos, A.P. Patsis, M.A. Karakassides, G.D. Chryssikos, J. Non-Cryst. Solids 126 (1990) 52.

26 Rada S, Dan V, Rada M. Gadolinium-environment in borate-tellurate glass ceramics studied by FTIR and EPR spectroscopy. Journal of Non-Crystalline Solids. 2010;356:474-479.

27 Dunken H, Doremus RH. Short time reactions of a Na2O-cao-Sio2 glass with water and salt solutions. Journal of Non-Crystalline Solids. 1987; 92:61-72.

28 Borjesson L, McGreevy R.L and Wicks A,J. de Physique 111,2 (1992) 107.

29 N.Nagaraja, J. Sangamesh, Chandrashekar, T. Sankarappa, J. S. Ashwajeeth IEEE Xplore: 24 November 2016.

30 B.D.Callity Elements of X-ray Diffraction.

31 N.Nagaraja, T. Sankarappa, M. Prashant Kumar, J. Non-Cryst. Solids 354, 1503-1508 (2008).

32 Prashanth Kumar M, \& Sankarappa T. J. Non-Cryst. Solids, 355 (4), 295-300. (2009).

33 Ensanya A Abou Neel, Wojciech Chrzanowski, David M Pickup, Luke A O'Dell, Nicola J Mordan, Robert J Newport, Mark E Smith and Jonathan C Knowles J. R. Soc.Interface 2009 6, 435-446 first published online 30 September 2008 doi: 10.1098/rsif.2008.0348.

34 M. Harish Bhat, F.J. Berry, J.Z. Jiang, K.J. Rao, J. Non-Cryst. Solids 291 (2001) 93.

35 R.M. Almieda, J.D. Mackenize, J. Non-Cryst. Solids 40 (1980) 535.

36 M. Villa, M. Scagliotti, G. Chiodelli, J. Non-Cryst. Solids 94 (1987) 101.

37 I.Waclawska, "Glass transition effect of amorphous borates,"Thermochimica Acta, vol. 269, pp. 457-464, 1995.

38 Physical, optical and radiative properties of $\mathrm{CaSO}_{4}-\mathrm{B}_{2} \mathrm{O}_{3}-\mathrm{P}_{2} \mathrm{O}_{5}$ glasses doped with Sm3+ ions Chinese Journal of Physics 56 (2018) 932-943.

39 R. K. Brow, D. R. Tallant, S. T. Myers and C. C. Phifer, "The Short Range Structure of Zinc Phosphate glass," Journal of Non-Crystalline Solids, Vol. 191, No. 1-2, 1995, pp. 45-55. doi:10.1016/00223093(95)00289-8

40 P. P. Proulx, G. Cormier, J. A. Capobianco, B. Cham-pagnon and M. Bettinelli, "Raman and Low Frequency Raman Spectroscopy of Lead, Zinc and Barium Meta-phosphate Glasses Doped with Eu3+ Ions," Journal of Physics: Condensed Matter, Vol. 6, No. 1, 1994, pp. 275-283. doi:10.1088/0953-8984/6/1/027

41 H. P. Lim, A. Karki, S. Feller, J. E. Kasper, and G. Sumcad, "The density of potassium borate glasses related to atomicarrangements," Journal of Non-Crystalline Solids, vol. 91, no.3, pp. 324-332, 1987.

42 Koudelka, L., and P. Mo sner. 2000. Borophosphate glasses of the $\mathrm{ZnO}-\mathrm{B}_{2} \mathrm{O}_{3}-\mathrm{P}_{2} \mathrm{O}_{5}$ system. Materials Letters. 42: 194-199.

43 Physical, optical and radiative properties of $\mathrm{CaSO}_{4}-\mathrm{B}_{2} \mathrm{O}_{3}-\mathrm{P}_{2} \mathrm{O}_{5}$ glasses doped with $\mathrm{Sm} 3+$ ions Chinese Journal of Physics 56 (2018) 932-943. 